\title{
Predictors of financial well-being among Malaysian employees: examining the mediate effect of financial stress
}

\begin{abstract}
Financial well-being and its impact on the quality of life among employees have received considerable attention from researchers, consumer and financial educators, practitioners and policy makers. The purpose of this study is to examine the determinant factors of employees' financial well-being in Malaysia. The results of this study can be used for better understanding of the relationship between and among determinants of financial well-being by highlighting the relationships among financial literacy, financial behavior, financial capability, financial problem, and financial stress. Samples were selected using multi-stage sampling technique among employees in public and private sectors. A total of 2,000 completed questionnaires were analyzed using path analysis to identify direct and indirect effects on financial well-being. The results identified that financial well-being determinants were financial literacy, financial behavior, financial capability, financial problem; and financial stress had either a direct and indirect effect on financial well-being. The findings indicated that financial stress partially mediate the effect of factors on predicting financial well-being.
\end{abstract}

Keyword: Financial literacy; Financial behavior; Financial capability; Financial problem; Financial stress; Financial well-being 